\title{
Electrochemical And DFT Investigations of Anticorrosive Potentials of Selected Sulphonamides Based On Adsorption At Aluminium/Aqueous Acid Interface
}

Lutendo C. Murulana

University of Venda

Tshimangadzo Nesane

University of Venda

Mwadham M. Kabanda

University of Venda

Lukman 0. Olasunkanmi

Obafemi Awolowo University

Eno E. Ebenso ( $\square$ ebensee@unisa.ac.za )

University of South Africa

\section{Research Article}

Keywords: Potentiodynamic Polarization, Aluminium, Electrochemical Impedance Spectroscopy, FTIR, SEM, binding energy

Posted Date: September 7th, 2021

DOI: https://doi.org/10.21203/rs.3.rs-861880/v1

License: (c) (1) This work is licensed under a Creative Commons Attribution 4.0 International License. Read Full License 


\section{Abstract}

The anticorrosive properties of six (6) selected sulphonamide derivatives on the aluminium surface were investigated in order to reveal their mechanism and mode of adsorption on $\mathrm{Al} / \mathrm{HCl}$ interface, as well as the strength of the interactions between the inhibitor and Al surface. Electrochemical impedance spectroscopy (EIS) and potentiodynamic polarization (PDP) techniques were utilised to evaluate the inhibition efficiencies of the selected compounds, while scanning electron microscopy (SEM) and Fourier transform infrared spectroscopy techniques were utilised to understand the surface morphology of Al and adsorption sites of the sulphonamides. Density functional theory (DFT) calculations were utilised to investigate the strength of interactions between the inhibitor molecules and Al. Corrosive electrolyte of $1 \mathrm{M}$ hydrochloric acid was employed in the study. All the studied sulphonamides showed excellent corrosion inhibition efficiencies with maximum values of up to $95 \%-97 \%$ at the optimum concentrations $\left(4 \times 10^{-5} \mathrm{M}-4 \times 10^{-5} \mathrm{M}\right)$, based on EIS measurements. The EIS parameters further revealed adsorbed film of the sulphonamides on the Al surface with capacitive-inductive characters. All the six sulphonamides reduced the corrosion current densities for both anodic and cathodic half-reactions and shifted the corrosion potentials to some anodically nobler values as revealed by the PDP data. Adsorption of the sulphonamides at the $\mathrm{Al} / \mathrm{HCl}$ interface was described by the Langmuir isotherm model. Surface protection properties of the sulphonamides were further confirmed by SEM plates that showed less damaged surface of Al for the inhibited process compared to the uninhibited one. DFT results suggest that the binding energy for the inhibitors on the Al surface results in an energy that is less than $30 \mathrm{~kJ} / \mathrm{mol}$, which is an indication that the interactions are van der Waal type of interaction, suggesting physisorption mechanism.

\section{Introduction}

Aluminium is a very light metal that has wide industrial applications including production of pipes, batteries and machineries. Beside its lightweight character, it has many advantages such as electrical conductivity, thermal conductivity, and resistance to corrosion [1-7]. Its ability to resist corrosion process, allowing for the added protection of Al surface, occur in the near-neutral and neutral solutions of most non-halide salts and it is attributed to the formation of the thin, adherent and protective oxide film on the Al surface. The thin film of aluminium oxide is non-labile, and it acts as a protective blockade between the metal and corrosive environment. However, in highly acidic or basic environments, aluminium can be corroded since the solubility of aluminium oxide film increases in either of these environments [8].

Several corrosion protection methods have been used to slow down the rate of corrosion of metal surfaces. Methods such as anodising, painting, conversion coating and corrosion inhibitors are often utilised with the purpose of increasing the thickness of oxide film on the metal surface. Most corrosion inhibitors are organic substances that contain functional groups, such as aromatic rings, multiple double bonds and heteroatoms, that can donate electrons to the partially filled or vacant orbitals of the metal atoms on the metal surface [9-18]. In the case of the aluminium surface, the inhibitor molecule would be expected to provide electrons to the partially-filled $3 p$ orbital and some of the vacant $3 p$ orbitals. 
Sulphonamide derivatives possess properties of good corrosion inhibitors such as the availability of several heteroatoms and aromatic rings. Although their anti-corrosion properties on Fe surface have been extensively investigated and suggest chemisorption type of interactions [19-23], studies on their anticorrosion potentials for Al are very scanty. Moreover, adsorption behaviour and corrosion inhibition properties of organic compounds depend on the nature of metal and corrosive media. It is therefore important to investigate the inhibitive effects of sulphonamides on Al corrosion to better understand their applicability in suppressing acid corrosion of Al just as it had been revealed for Fe [22, 23].

Our group had previously reported the potentiality of the six (6) sulphonamide derivatives reported in the present study to mitigate acid corrosion of mild steel [23]. In furtherance of our efforts to provide better understanding of the adsorption behaviour of sulphonamides on the surface of different metals, sulphanilamide (SNA), sulphabenzamide (SBZ), sulphachloropyridazine (SCP), sulphisoxazole (SSZ), sulphamethizole (SMZ) and sulphadimethoxine (SDM) are hereby investigated in the present study for their adsorption behaviour at $\mathrm{Al} / \mathrm{HCl}$ interface and their effectiveness in inhibiting acid corrosion of $\mathrm{Al}$. The structures of the studied compounds are shown in Fig. 1.

\section{Experimental And Computational Details}

\subsection{Treatment of samples and preparation of corrosive medium}

All experimental procedures were conducted on aluminium samples of $99.5 \%$ purity. Prior to carrying out the different experimental procedures, the Al samples were abraded with emery papers (from 100, 200, 600 and 1200 grit sizes). Double distilled water and acetone were utilized for all sample washing purposes. All aluminium samples were air-dried for a minimum period of $24 \mathrm{~h}$ and kept in desiccators prior to carrying out further experimental measurements.

A concentrated analytical grade $32 \% \mathrm{HCl}$ from Sigma Aldrich was diluted to a slightly less aggressive solution of $1.0 \mathrm{M}$ through careful addition of appropriate amounts of double distilled water. It is this solution that was utilised as the corrosive medium for the Al surface.

\subsection{Preparation sulphonamide inhibitor solutions}

All corrosion inhibitors, namely, sulphanilamide (SNA), sulphabenzamide (SBZ), sulphachloropyridazine (SCP), sulphisoxazole (SSZ), sulphamethizole (SMZ) and sulphadimethoxine (SDM) were obtained from Sigma Aldrich chemicals and consequently utilized without any further purification. Small inhibitor concentrations in the range of $1.0 \times 10^{-5} \mathrm{M}$ to $5.0 \times 10^{-5} \mathrm{M}$ were prepared and utilized in all experimental procedures.

\subsection{Electrochemical techniques}

A Potentiostat/Galvanostat (PGSTAT302N) from Metrohm was utilized for carrying out electrochemical procedures, such as potentiodynamic polarization (PDP) and electrochemical impedance spectroscopy (EIS). This instrument makes use of a three-electrode cell of a $150 \mathrm{~mL}$ capacity, in the form of platinum 
counter electrode (CE), aluminium working electrode (WE) and saturated calomel with $\mathrm{Ag} / \mathrm{AgCl}$ reference electrode (RE). The surface ( $1 \mathrm{~cm}^{2}$ surface area) pre-treatment of the RE was done exactly as described in Sect. 2.1. Numerous attempts and trials were carried out in order to obtain a stable value of $E_{\text {corr.* }}$ Consequently, a $30 \mathrm{~min}$ period was adopted as an appropriate period of stabilization prior all electrochemical procedures. In this work, all Tafel slopes were obtained utilizing a potential within - 250 to $+250 \mathrm{mV}$ (SCE) range at a scan rate of $1 \mathrm{mV} \cdot \mathrm{s}^{-1}$. All electrochemical impedance parameters were determined through utilizing a frequency response analyzer (FRA) which was linked to the Galvanostat. This was achieved at a frequency range of $100 \mathrm{kHz}$ to $1.0 \times 10^{-5} \mathrm{kHz}$ subjected to potentiodynamic conditions with amplitude of $10 \mathrm{mV}$ peak-to-peak, utilizing $\mathrm{AC}$ signal at $\mathrm{E}_{\text {corr }}$.

The potentiodynamic inhibition efficiency ( $\left(\mathrm{E}_{\mathrm{PDP}}\right)$ and electrochemical impedance inhibition efficiency (IE $\left.\mathrm{E}_{\mathrm{EIS}}\right)$ were calculated, starting from potentiodynamic and impedance data, utilizing the following equations:

$$
\begin{aligned}
& \% I E_{P D P}=\left(\frac{i_{\text {corr }}^{0}-i_{\text {corr }}^{i}}{i_{\text {corr }}^{0}}\right) \times 100 \\
& \% I E_{E I S}=\left(1-\frac{R_{c t}^{0}}{R_{c t}}\right) \times 100
\end{aligned}
$$

where $i_{\text {corr }}^{0}$ is the corrosion current density in the absence of sulphonamide compounds and $i_{\text {corr }}^{i}$ is the corrosion current density in the presence of the sulphonamide compounds, $\mathrm{R}_{\mathrm{ct}}{ }_{\mathrm{C}}$ is the resistance of charge transfer in the absence of sulphonamide compounds and $\mathrm{R}_{\mathrm{ct}}$ is the resistance of charge transfer in the presence of sulphonamide compounds.

\subsection{Scanning electron microscopy (SEM) and energy dispersive spectroscopy (EDS)}

All kinds of surface interactions at the aluminum-sulphonamide/Hydrochloric acid interfaces were investigated utilizing JOEL JSM-7500F Field Emission Scanning Electron Microscope. The procedure for sample surface preparation was carried out as described in Sect. 2.1. The instrument utilized here permitted a maximum surface area of $1 \mathrm{~cm}^{2}$ for all aluminium samples.

\subsection{Fourier Transform Infrared Spectrometer (FTIR)}

Fourier transform infrared spectroscopy (FT-IR) technique is useful in investigating the variation in functional groups resulting during the adsorption process [22]. The adsorption films formed on metal surface during the process of corrosion of aluminium surface in the presence of the inhibitor were scratched off the surface and the powders as well as the liquid samples were analysed using Cary 600 series FT-IR spectrometer.

\subsection{DFT study on the binding of sulphonamides on the Al surface}


The calculations were performed using Materials Studio 2020 program utilising the $\mathrm{DMol}^{3}$ module [24] and were based on the DFT principle by utilising the approximation (GGA) and Perdew-Burke-Ernzerhof (PBE) functionals to ensure the reliability of the measurement. Calculations were performed also by utilising the double extended base of the double numeric basis plus polarization (DNP), so that it can be described that calculations were performed at the GGA/RPBE/DNP level present in $\mathrm{DMol}^{3}[25,26]$. To deal with core electrons on the Al surface and accelerate the convergence of self-consistent field (SCF) charge density, the DFT semi-core pseudopotential (DSPP) and iterative subspace direct inversion (DIIS) were used. For the sampling of the Brillouin-zone the Monkhorst-Pack grid used was $3 \times 3 \times 1$. For the geometry optimization, the electronic energy convergence criteria, gradient, and atom displacement were set as $0.00001 \mathrm{Ha}(\mathrm{Ha}$ is Hartree), $0.002 \mathrm{Ha} / \AA$, and $0.005 \AA$, respectively.

The Al (111) slab surfaces were modelled by three layers repeated in a $5 \times 5$ surface cell unit with a $20 \AA$ separation between clean slabs to ensure no contact between the sorbate and its periodic image. Along with the adsorbates, the uppermost layer of the Al atoms was relaxed, and the remaining two layers constrained. The adsorption energies $\left(E_{\text {ads }}\right)$ were calculated from the following expression [27-30]:

$E_{\text {ads }}=E_{\mathrm{Al}(111) \text { surface }}+$ molecule $-E_{\text {molecule }}-E_{\mathrm{Al}(111) \text { surface }}$

where $\mathrm{E}_{\mathrm{Al}(111) \text { surface + molecule }}$ is the total energy of the interacting molecule of interest and the aluminium(111) surface, $\mathrm{E}_{\text {molecule }}$ is the energy of the isolated molecule and $\mathrm{E}_{\mathrm{Al}(111) \text { surface }}$ is the energy of the isolated aluminium surface.

\section{Results And Discussion}

\subsection{Potentiodynamic polarization techniques}

Tafel plots for aluminium in $1 \mathrm{M} \mathrm{HCl}$ in the absence and presence of different concentrations of the inhibitors are presented in Fig. 2; the plots show that the trend adopted by the uninhibited processes is similar to that adopted by the inhibited processes. This behaviour can be interpreted to mean that the inhibition mechanism that is followed by all utilized inhibitors is similar to that of the corrosion process [31-34]. In addition, the anodic and cathodic processes are altered. Since corrosion is an electrochemical process, altering either anodic or cathodic half-reactions brings about a delay in the rate of corrosion $[35,36]$, which implies that the inhibitors have a tendency to slow down the corrosion process on the Al surface. Another interesting observation from Fig. 2 is the elongated section on the upper solid curve which is also referred to as the anodic branch of the experimental polarization. This elongation effect on the anodic section may be attributed to the formation of the passivation film on the aluminium surface during the reaction, which aides in the protection of the Al surface. Extrapolation on the Tafel slopes. gives rise to certain crucial PDP parameters such as Tafel anodic slope $\left(b_{a}\right)$, Tafel cathodic slope $\left(b_{c}\right)$, corrosion current density $\left(\mathrm{i}_{\text {corr }}\right)$ and corrosion potential $\left(\mathrm{E}_{\text {corr }}\right)$, which are all collectively reported in Table 1.

Table 1: Potentiodynamic polarization (PDP) parameters such as corrosion potential $\left(E_{\text {corr }}\right)$, corrosion current density $\left(i_{\text {corr }}\right)$ and anodic and cathodic Tafel slopes $\left(b_{\mathrm{a}}\right.$ and $\left.b_{\mathrm{c}}\right)$ using different inhibitors. 


\begin{tabular}{|c|c|c|c|c|c|c|c|}
\hline Inhibitor & $\begin{array}{l}\text { Inhibitor } \\
\text { Conc. (M) }\end{array}$ & $\begin{array}{l}-\mathrm{E}_{\text {corr }}(\mathrm{mV}) \\
\text { vs } \mathrm{Ag} / \mathrm{AgCl}\end{array}$ & $\begin{array}{l}\mathrm{i}_{\text {corr }} \\
\left(\mathrm{mA} \cdot \mathrm{cm}^{-2}\right)\end{array}$ & $\begin{array}{l}R_{p} \\
\left(10^{-1}\right)(O h m)\end{array}$ & $\begin{array}{l}b_{a} \\
\left(V_{d e c}{ }^{-1}\right)\end{array}$ & $\begin{array}{l}-b_{c} \\
\left(V_{d e c}{ }^{-1}\right)\end{array}$ & $\% \mathrm{IE}_{\mathrm{PDP}}$ \\
\hline Blank & & 712 & 8.63 & 4.99 & 9.82 & 8.95 & - \\
\hline \multirow{5}{*}{ SNA } & $1.0 \times 10^{-5}$ & 650 & 2.53 & 3.18 & 1.52 & 0.69 & 70.68 \\
\hline & $2.0 \times 10^{-5}$ & 648 & 1.85 & 2.53 & 0.21 & 0.05 & 78.56 \\
\hline & $3.0 \times 10^{-5}$ & 637 & 1.47 & 3.29 & 0.11 & 0.14 & 82.96 \\
\hline & $4.0 \times 10^{-5}$ & 641 & 1.43 & 3.14 & 0.10 & 0.10 & 83.42 \\
\hline & $5.0 \times 10^{-5}$ & 644 & 1.27 & 3.22 & 0.09 & 0.09 & 85.28 \\
\hline \multirow{5}{*}{ SBZ } & $1.0 \times 10^{-5}$ & 621 & 1.99 & 3.65 & 1.13 & 0.66 & 76.94 \\
\hline & $2.0 \times 10^{-5}$ & 599 & 1.61 & 3.22 & 1.52 & 0.56 & 81.34 \\
\hline & $3.0 \times 10^{-5}$ & 666 & 1.13 & 3.12 & 1.51 & 0.88 & 86.90 \\
\hline & $4.0 \times 10^{-5}$ & 614 & 1.10 & 2.56 & 0.99 & 0.95 & 87.25 \\
\hline & $5.0 \times 10^{-5}$ & 621 & 1.01 & 3.68 & 0.41 & 0.65 & 88.29 \\
\hline \multirow{5}{*}{ SCP } & $1.0 \times 10^{-5}$ & 631 & 2.64 & 1.98 & 2.14 & 1.45 & 69.40 \\
\hline & $2.0 \times 10^{-5}$ & 645 & 2.81 & 2.01 & 1.99 & 0.98 & 67.43 \\
\hline & $3.0 \times 10^{-5}$ & 615 & 2.60 & 2.14 & 1.84 & 1.02 & 69.87 \\
\hline & $4.0 \times 10^{-5}$ & 608 & 2.51 & 2.56 & 1.95 & 0.78 & 70.91 \\
\hline & $5.0 \times 10^{-5}$ & 645 & 2.43 & 2.41 & 2.54 & 1.44 & 71.84 \\
\hline \multirow{5}{*}{ SDM } & $1.0 \times 10^{-5}$ & 566 & 2.99 & 2.98 & 1.98 & 1.54 & 65.35 \\
\hline & $2.0 \times 10^{-5}$ & 614 & 2.85 & 2.36 & 1.97 & 1.56 & 66.97 \\
\hline & $3.0 \times 10^{-5}$ & 598 & 2.61 & 3.12 & 1.69 & 2.08 & 69.75 \\
\hline & $4.0 \times 10^{-5}$ & 601 & 2.60 & 3.01 & 1.65 & 0.96 & 69.87 \\
\hline & $5.0 \times 10^{-5}$ & 613 & 2.51 & 3.11 & 2.05 & 1.55 & 70.91 \\
\hline \multirow{2}{*}{ SSZ } & $1.0 \times 10^{-5}$ & 589 & 0.91 & 3.61 & 2.01 & 1.66 & 89.45 \\
\hline & $2.0 \times 10^{-5}$ & 601 & 0.87 & 2.98 & 1.99 & 1.54 & 89.91 \\
\hline
\end{tabular}




\begin{tabular}{|cccccccc|} 
& $3.0 \times 10^{-5}$ & 578 & 0.78 & 2.52 & 1.85 & 1.21 & 90.96 \\
\hline $4.0 \times 10^{-5}$ & 612 & 0.74 & 3.12 & 1.84 & 1.81 & 91.42 \\
\hline $5.0 \times 10^{-5}$ & 613 & 0.69 & 3.14 & 1.47 & 1.68 & 92.00 \\
\hline & $1.0 \times 10^{-5}$ & 618 & 1.69 & 2.96 & 1.99 & 1.87 & 80.41 \\
\hline & $2.0 \times 10^{-5}$ & 598 & 1.45 & 2.87 & 1.67 & 1.85 & 83.19 \\
& $3.0 \times 10^{-5}$ & 612 & 1.11 & 2.55 & 1.55 & 1.99 & 87.13 \\
\hline & $4.0 \times 10^{-5}$ & 615 & 0.98 & 3.10 & 1.41 & 1.84 & 88.64 \\
\hline & $5.0 \times 10^{-5}$ & 599 & 0.81 & 3.12 & 1.58 & 1.78 & 90.61 \\
\hline
\end{tabular}

The obtained corrosion current densities were further utilized to calculate the \% $\mathrm{IE}_{\mathrm{PDP}}$ for all inhibitors at various temperatures according to Eq. 1 . As it is observed in Table 1 , the values of $b_{a}$ and $b_{c}$ for the uninhibited processes are less in comparison with those of the inhibited processes by a margin. This information suggests that the cathodic and anodic half-reactions were altered through the introduction of the individual inhibitor molecules. A closer inspection into the results involving the corrosion current density shows that the addition of all inhibitors utilized shifted the polarization curves towards lower regions of the current. This is a characteristic trend for favourable adsorption by inhibitors on the metal surfaces $[37,38]$.

The magnitude of the displacement in the $E_{\text {corr }}$ values between the inhibited and uninhibited systems can be used to classify the mode of inhibition as either anodic, cathodic or mixed-type. An inhibitor can be classified as anodic or cathodic type if the change in the $E_{\text {corr }}$ values is greater than $\pm 85 \mathrm{mV}[38,39]$. A mixed-type adsorption mechanism is further proposed from the values of corrosion potential, which are almost constant with negligible variation [38, 39].

\subsection{Electrochemical impedance spectroscopy (EIS)}

EIS plays an integral role in studying the properties of metal/solution and inhibitor boundary [40,41], in that it provides information in connection to the effect of the increase on the concentration of each of the inhibitor molecule on the extent of adsorption of the inhibitor on the metal surface. Moreover, this technique also permits for the investigation of the corrosion dynamic behaviour of aluminium surface as time changes [42]. The effects of introduction of various concentrations of the selected sulphonamide inhibitors on decreasing the corrosion of the aluminium surface are better discussed through the use of the Nyquist plots, which are shown in Fig. 3, and the corresponding Bode plots, which are shown in Fig. 4. Both plots (uninhibited and inhibited ones) are characterized by imperfect semicircles coupled with curved-like end, which represent the formation of the passivation protective film on the aluminium surface. This characteristic nature of the Nyquist plots is commonly due to the impurities on the metallic surface, inhomogeneity of the aluminium surface, adsorption of sulphonamides on aluminium surface and the roughness of the electrode surfaces [42-45]. Additionally, Nyquist plots are composed of inductive loops at low frequency and capacitive loops at high frequency. The inductive loop at low frequency is due to the bulk relaxation process which is a result of the formation of the adsorption film on the charged metal surface 
induced by the existence of charged species such as hydrogen ions, hydroxide ions, protonated inhibitor or chloride ions $[43,44]$. The capacitive loop at high frequency is due to the transfer of charge and double layer capacitance $\left(C_{d 1}\right)[43,44]$. The experimental data obtained herein was treated and fitted utilizing an electrical equivalent model circuit shown in Fig. 5. The diameters of the semicircles of the inhibited processes are larger than those of the uninhibited process and increases as the inhibitor concentration increases. This observation signifies that sulphonamide inhibitors slow down aluminium corrosion in $1.0 \mathrm{M} \mathrm{HCl}$ and the corrosion rate decreases with increase in inhibitor concentration. Table 2 lists the results in relation to significant impedance parameters such as the solution resistance $\left(R_{s}\right)$, the resistance of the charge transfer $\left(R_{c t}\right)$ and the exponent of the constant phase element $(n)$. These results were obtained as a consequence of fitting the EIS data onto an electrical circuit as shown in Fig. 5. The solution resistance is related to the conductivity of the solution or system; the results shows that $R_{S}$ values corresponding to the blank experiments are much less than those corresponding to the inhibited experiments, which implies that the conductivity of the solution decreases as the inhibitor molecules are introduced into the system. The fact that the geometry of the area in which the movement of the current is located within the systems varies causes an increase in the inhibitor concentration to bring about a no particular trend in the values corresponding to $R_{s}$. The effect of the inhibitor concentration on the $R_{c t}$ values is such that as the inhibitor concentration increases the corresponding $R_{\mathrm{ct}}$ values also increase. This phenomenon may be attributed to the fact that the surface coverage occupied by the sulphonamides on aluminium increases as the number of inhibitor molecules increases in the system $[44,45]$. In other words, increasing the concentration of the inhibitor molecule has a direct relationship with the increase in the coverage of the aluminium surface. The values of $n$ corresponding to all utilized inhibitors do not present a specific trend but each has a value that is close to unity, which implies that the interface is attributed to capacitive trend. The $\% \mathrm{IE}_{\mathrm{EIS}}$ increases with increase in inhibitor concentration due to the fact that as the number of inhibitor molecules are increased within the system, the amount of aluminium surface covered is maximized thereby increasing the inhibitoraluminium surface adsorption.

Table 2: Electrochemical impedance (EIS) parameters such as the resistance of charge transfer $\left(\mathrm{R}_{\mathrm{ct}}\right)$ and the CPE exponent (n) using different inhibitors. 


\begin{tabular}{|c|c|c|c|c|c|c|c|c|c|}
\hline \multirow[t]{3}{*}{ Inhibitor } & \multicolumn{9}{|l|}{ Inhibitor } \\
\hline & Conc. & $\mathbf{R}_{\mathbf{s}}$ & & & $Y_{01} \times 10^{-8}$ & $Y_{02} \times 10^{-5}$ & $\mathrm{n}_{1}$ & $\mathrm{n}_{2}$ & $\% \mathrm{IE}_{\mathrm{EIS}}$ \\
\hline & (M) & $\left(\mathrm{W} \mathrm{cm^{2 }}\right)$ & $\left(\mathrm{W} \mathrm{cm^{2 }}\right)$ & $\begin{array}{l}(\Omega \\
\left.\mathrm{cm}^{2}\right)\end{array}$ & $\begin{array}{l}(\mu \mathrm{F} \mathrm{cm}- \\
2)\end{array}$ & $\begin{array}{l}(\mu \mathrm{F} \mathrm{cm}- \\
2)\end{array}$ & & & \\
\hline Blank & & -63.70 & 06.64 & 08.54 & 1.91 & 2.50 & 1.100 & 0.955 & - \\
\hline \multirow{5}{*}{ SNA } & $1.0 \times 10^{-5}$ & -8.199 & 29.29 & 26.38 & 6.50 & 3.33 & 0.944 & 1.044 & 77.33 \\
\hline & $2.0 \times 10^{-5}$ & -9.661 & 31.56 & 26.59 & 3.72 & 7.07 & 0.948 & 1.045 & 78.96 \\
\hline & $3.0 \times 10^{-5}$ & -1.392 & 33.54 & 48.90 & 6.52 & 3.31 & 0.993 & 0.912 & 80.20 \\
\hline & $4.0 \times 10^{-5}$ & -66.34 & 121.4 & 20.08 & 9.52 & 3.56 & 1.000 & 1.052 & 94.53 \\
\hline & $5.0 \times 10^{-5}$ & -90.12 & 256.9 & 57.83 & 1.45 & 3.12 & 0.561 & 1.082 & 97.41 \\
\hline \multirow{5}{*}{ SBZ } & $1.0 \times 10^{-5}$ & -8.199 & 29.29 & 26.38 & 6.51 & 3.31 & 0.945 & 1.041 & 77.33 \\
\hline & $2.0 \times 10^{-5}$ & -7.577 & 39.26 & 59.60 & 1.11 & 3.56 & 0.880 & 1.023 & 80.06 \\
\hline & $3.0 \times 10^{-5}$ & -7.895 & 40.80 & 56.70 & 1.12 & 3.62 & 0.981 & 1.036 & 83.72 \\
\hline & $4.0 \times 10^{-5}$ & -84.41 & 122.2 & 17.65 & 2.28 & 3.75 & 1.096 & 0.978 & 94.56 \\
\hline & $5.0 \times 10^{-5}$ & -64.57 & 137.2 & 48.30 & 9.11 & 3.34 & 0.999 & 1.044 & 95.16 \\
\hline \multirow{5}{*}{ SCP } & $1.0 \times 10^{-5}$ & -65.62 & 123.6 & 32.81 & 1.96 & 3.54 & 0.995 & 1.063 & 94.62 \\
\hline & $2.0 \times 10^{-5}$ & -64.80 & 123.8 & 41.49 & 1.98 & 2.54 & 0.956 & 1.123 & 94.63 \\
\hline & $3.0 \times 10^{-5}$ & -64.09 & 124.7 & 47.14 & 2.91 & 2.88 & 0.925 & 1.095 & 94.88 \\
\hline & $4.0 \times 10^{-5}$ & -56.99 & 129.9 & 105.2 & 1.63 & 4.62 & 0.963 & 0.987 & 95.16 \\
\hline & $5.0 \times 10^{-5}$ & -64.51 & 137.2 & 48.30 & 9.12 & 3.26 & 0.999 & 1.056 & 94.53 \\
\hline \multirow{7}{*}{ SDM } & $1.0 \times 10^{-5}$ & -66.34 & 121.4 & 20.08 & 9.51 & 3.56 & 1.000 & 1.056 & 94.64 \\
\hline & $2.0 \times 10^{-5}$ & -87.07 & 124.1 & 18.94 & 9.52 & 3.56 & 1.088 & 1.056 & 94.88 \\
\hline & $3.0 \times 10^{-5}$ & -56.99 & 129.9 & 105.2 & 1.63 & 4.61 & 0.963 & 0.985 & 95.73 \\
\hline & $4.0 \times 10^{-5}$ & -73.65 & 155.6 & 37.80 & 1.32 & 4.36 & 0.785 & 1.000 & 95.83 \\
\hline & $5.0 \times 10^{-5}$ & -53.46 & 159.3 & 31.83 & 1.56 & 3.45 & 0.985 & 1.042 & 94.51 \\
\hline & $1.0 \times 10^{-5}$ & -61.64 & 121.0 & 69.79 & 2.40 & 5.91 & 0.945 & 0.995 & 94.56 \\
\hline & $2.0 \times 10^{-5}$ & -65.64 & 122.2 & 32.81 & 1.65 & 3.75 & 0.963 & 1.056 & 95.33 \\
\hline
\end{tabular}




\begin{tabular}{|llllllllll|} 
SSZ & $3.0 \times 10^{-5}$ & -64.76 & 142.2 & 41.49 & 1.95 & 2.48 & 0.951 & 1.120 & 95.16 \\
\cline { 2 - 4 } & $4.0 \times 10^{-5}$ & -64.51 & 137.2 & 48.30 & 9.12 & 3.26 & 0.999 & 1.012 & 95.83 \\
\hline $5.0 \times 10^{-5}$ & -53.44 & 159.4 & 31.02 & 1.46 & 3.56 & 0.956 & 1.046 & 94.63 \\
& $1.0 \times 10^{-5}$ & -64.09 & 123.8 & 47.14 & 2.96 & 2.88 & 0.925 & 1.096 & 94.88 \\
\hline & $2.0 \times 10^{-5}$ & -56.99 & 129.9 & 105.2 & 1.62 & 4.62 & 0.965 & 0.958 & 94.93 \\
& $3.0 \times 10^{-5}$ & -57.76 & 131.0 & 17.43 & 1.27 & 5.61 & 0.978 & 1.000 & 95.72 \\
& $4.0 \times 10^{-5}$ & -73.44 & 155.5 & 37.80 & 1.30 & 4.32 & 0.789 & 1.026 & 95.83 \\
\hline $5.0 \times 10^{-5}$ & -57.76 & 159.3 & 31.83 & 1.56 & 3.28 & 0.958 & 1.098 & 83.94 \\
\hline
\end{tabular}

\subsection{Surface morphology from scanning electron microscopy (SEM) and energy dispersive spectroscopy (EDS)}

Scanning electron microscopy images corresponding to the aluminium samples are shown in Fig. 6 while their respective energy dispersive spectroscopy spectra data are shown in Fig. 7. The main objective of the SEM technique is to provide some in-depth knowledge regarding all kinds of surface interactions at the aluminium-sulphonamide/hydrochloric acid interfaces. EDS spectra provide some valuable information regarding the molecular functionality variations [46-50]. The results show that aluminium surfaces prior to contact with the corrosive environments are of a smooth nature coupled with some minor roughness that may be attributed to sample preparations that involve thorough abrasions. The smoothness is compromised as soon as the samples are introduced to the corrosive environments, as shown in Fig. 6 . The main cause associated with this observation is the aggressive ions such as $\mathrm{Cl}^{-}$that are available within $\mathrm{HCl}$. Further analysis suggests that all surfaces of aluminium samples in the presence of utilized inhibitors are of a more smooth nature than those associated with uninhibited processes. This means that all utilized inhibitors have the ability to minimize aluminium corrosion through adsorption on the surfaces [51 - 53]. From the EDS spectra shown in Fig. 7, the presence and absence of $\mathrm{Cl}^{-}$is somewhat observable for uninhibited and inhibited processes, respectively. These results in conjunction with the FTIR data further support the idea that sulphonamide inhibitors possess the tendency to reduce the rate of corrosion on metals through the formation of the adsorption type bond [22].

\subsection{Surface morphology from fourier transform infrared spectrometry (FTIR)}

The variation in molecular functional groups resulting from the adsorption of the inhibitor molecule on the aluminium surface was studied using FT-IR technique. This technique is often utilised to analyse the adsorption film formed on the aluminium surface by making use of molecular functional group studies [54 57]. The presence of the certain molecular functional groups of the inhibitor on the surface of the metal surface confirms that fact that inhibitor molecule adsorbs on the surface. The FT-IR spectra of both the 
corrosion inhibitor and film formed on the surface are shown in Fig. 8. The absorption bands at the fingerprint region could signify the molecular functional groups that are involved in the adsorption of the inhibitor on the aluminium surface. The absorption band at around $1550 \mathrm{~cm}^{-1}$ and $1000 \mathrm{~cm}^{-1}$ correspond to aromatic conjugated $\mathrm{C}=\mathrm{C}$ and $\mathrm{C}-\mathrm{N}$ (stretch) respectively. The loss of both $\mathrm{C}=\mathrm{C}$ and $\mathrm{C}-\mathrm{N}$ functional groups on the corrosion inhibitor spectrum as compared to one of adsorption film is an indication of the interaction between the corrosion inhibitor and aluminium surface $[58,59]$. The band at around $3300 \mathrm{~cm}^{-1}$ represent $\mathrm{O}-\mathrm{H}$ functional group. The $\mathrm{O}-\mathrm{H}$ group at this region is due to the presence of water molecules during the analysis of adsorption film which may be due to the fact that the current corrosion studies are conducted in aqueous $\mathrm{HCl}$ solutions $[60,61]$.

\subsection{Adsorption isotherms and thermodynamic parameters}

The adsorption process is the primary step for the interaction of organic inhibitor with the metal surface and it depends on the type of metal, chemical structure of the inhibitor as well the type of electrolyte [62]. Analysis of the various plots of the various adsorption isotherms provide useful insight into the type of adsorption followed by the selected inhibitor molecules on the aluminium surface. In the current study, various adsorption isotherms were tested including Langmuir, Temkin, Frumkin, and Freundlich. The degree of surface coverage obtained from the weight loss at different concentration of the inhibitor and different temperature was used to determine the type of adsorption isotherm which correlates with the experimental results. The results of the investigation suggest that the selected sulphonamide molecule best adsorption on the aluminium surface following the Langmuir adsorption isotherm pattern. This is due to the fact that out of all fitted adsorption isotherms, Langmuir produced the best linear relationships with regression coefficient close to unity. Langmuir adsorption equation relating the concentration of the inhibitors to their surface coverage at constant temperature is shown as Eq. 4 and was used to plot adsorption isotherms shown in Fig. 9.

$\frac{C_{i n h}}{\theta}=\frac{1}{K_{a d s}}+C_{i n h}$

The adsorption or desorption equilibrium constant was obtained by using equation 5 .

$\Delta G^{\circ}$ ads $=-R T \ln \left(55.5 K_{\text {ads }}\right)$

where $\mathrm{C}_{\text {inh }}$ is the concentration of the inhibitor, $\theta$ is the degree of the surface coverage, $\mathrm{K}_{\mathrm{ads}}$ is the adsorption equilibrium constant, $\Delta \mathrm{G}^{\circ}$ ads is the standard free energy of adsorption and the value 55.5 represents the molar concentration of water in solution.

The values of change in Gibbs free energy of adsorption $\left(\Delta \mathrm{G}_{\text {ads }}\right)$ are recorded in Table 3. $\Delta \mathrm{G}_{\text {ads }}$ values obtained are of negative nature, which is indicative of a spontaneous process. Desorption process of inhibitor from the aluminium surface is also indicated by the decrease of $\Delta \mathrm{G}_{\text {ads }}$ as reaction temperature increase from $30^{\circ} \mathrm{C}$ to $50^{\circ} \mathrm{C}$. 
The values of $\Delta \mathrm{G}_{\text {ads }}$ may also provide an indication on the type of adsorption followed by the inhibitor molecules when binding on the metal surface; it is understood that $\Delta \mathrm{G}_{\text {ads }}$ values starting from $-40 \mathrm{~kJ} / \mathrm{mol}$ and above symbolize chemisorption process. Such energetic values represent possibility of the chemical interaction between the inhibitor molecule and the Al molecule. However, values of $\Delta \mathrm{G}_{\text {ads }}$ ranging from -20 $\mathrm{kJ} / \mathrm{mol}$ and lower symbolize physisorption process; a physisorption process is described by the existence of weak van der Waals interaction rather than chemical bonding between the inhibitor and the metal surface [63-67]. Table 3 shows that all $\Delta G_{\text {ads }}$ values increase with an increase in temperature, and they range from - $16.82 \mathrm{~kJ} / \mathrm{mol}$ to $-7.15 \mathrm{~kJ} / \mathrm{mol}$, which signifies mixed type of adsorption with physical adsorption predominant.

Table 3: Thermodynamic and adsorption parameters (Langmuir adsorption isotherms) for aluminium in 1.0 $\mathrm{M} \mathrm{HCl}$ at various temperatures for the utilized corrosion inhibitors.

\begin{tabular}{|c|c|c|c|c|c|c|c|}
\hline Inhibitor & Temperature $\left({ }^{\circ} \mathrm{C}\right)$ & $r^{2}$ & Slope & $\mathrm{K}_{\mathrm{ads}}$ & $\left(M^{-1}\right)$ & $\Delta \mathrm{G}^{0}{ }_{\mathrm{ads}}$ & $\left(\mathrm{kJ} . \mathrm{mol}^{-1}\right)$ \\
\hline \multirow{3}{*}{ SNA } & 30 & 0.999 & 0.995 & 13.15 & & -16.60 & \\
\hline & 40 & 0.999 & 1.107 & 4.890 & & -14.54 & \\
\hline & 50 & 0.998 & 1.249 & 5.285 & & -15.25 & \\
\hline \multirow{3}{*}{ SBZ } & 30 & 0.999 & 0.997 & 14.35 & & -16.82 & \\
\hline & 40 & 0.999 & 1.112 & 5.154 & & -15.18 & \\
\hline & 50 & 0.998 & 1.249 & 6.553 & & -15.83 & \\
\hline \multirow{3}{*}{ SCP } & 30 & 0.999 & 1.369 & 2.861 & & -12.76 & \\
\hline & 40 & 0.998 & 1.833 & 1.239 & & -11.01 & \\
\hline & 50 & 0.998 & 3.167 & 0.254 & & -07.15 & \\
\hline \multirow{3}{*}{ SDM } & 30 & 0.999 & 1.155 & 1.672 & & -11.79 & \\
\hline & 40 & 0.999 & 1.981 & 3.279 & & -13.97 & \\
\hline & 50 & 0.999 & 2.050 & 0.719 & & -09.01 & \\
\hline \multirow{3}{*}{ SSZ } & 30 & 0.999 & 1.052 & 14.24 & & -16.80 & \\
\hline & 40 & 0.999 & 1.194 & 3.921 & & -14.01 & \\
\hline & 50 & 0.998 & 1.318 & 1.237 & & -11.35 & \\
\hline \multirow{3}{*}{ SMZ } & 30 & 0.999 & 1.023 & 6.808 & & -14.94 & \\
\hline & 40 & 0.996 & 1.174 & 2.807 & & -13.55 & \\
\hline & 50 & 0.999 & 1.344 & 1.433 & & -11.75 & \\
\hline
\end{tabular}




\subsection{Structures of the Al...sulphonamide and their corresponding binding energy}

All interaction sites between each of the given sulphonamides on the Al (111) were tested. The preferred site for interaction between each of the inhibitor with the Al (111) surface is shown in Fig. 10. The results shows that the highest binding energy corresponds to the interaction between Al (111) and SSZ inhibitor, which can be considered to lie in the range of mixed inhibitor type of interaction. The second inhibitor in terms of high binding energy is SMX. All other inhibitors have binding energy less than $30 \mathrm{kcal} / \mathrm{mol}$, which would suggest that their mode of interaction with the $\mathrm{Al}(111)$ surface is strongly physisorption type in nature.

In structures that show mixed type of interactions (SSZ and SMX) with the Al (111) surface, the inhibitor molecule interacts with the surface through the $\mathrm{N}$ atom while in all the other physisorption-favored interactions, the molecule interacts with the $\mathrm{Al}(111)$ surface largely through the $\mathrm{O}$ atom. This result suggest that the $\mathrm{N}$ atom is more preferred center for donating electrons towards the $\mathrm{Al}(111)$ surface. The bond length value between the inhibit molecule and the $\mathrm{Al}(111)$ is consistent with the intermolecular type of interaction rather than covalent interaction. The results reported herein are therefore consistent with the experimental findings, which also suggest that the interaction energies between the selected sulphonamide inhibitors and the Al surface are largely through the physisorption type of interaction, with slight inclination towards chemisorption for the SSZ and SMX inhibitors.

\section{Conclusions}

The results from the current investigation reveal that sulphonamide compounds are excellent corrosion inhibitors for aluminium in acidic environments and their efficiency improves as the concentration is increased. The imperfect semi-circles on the Nyquist plots indicated an efficient inhibition of this metal by all six sulphonamides utilized. Moreover, PDP results also corroborated the EIS data by indicating that the introduction of all six sulphonamide compounds altered the corrosion current densities for both anodic and cathodic half-reactions and the adsorption mechanism adopted a Langmuir adsorption model.

The values of $E_{\text {corr }}$ did not exhibit a significant change, thus a mixed-type inhibition was proposed for the adsorption of these inhibitors on aluminium surfaces. Results from $\Delta G$ studies indicated that the inhibition of aluminium surfaces by all six sulphonamides was spontaneous and adopted a mixed-type mechanism with a predominant physical adsorption. The experimental results obtained agree well with theoretical DFT results, which also suggest that the binding of the inhibitor molecule on the aluminium surface falls within the physisoption adsorption range.

\section{References}

1. Haque, M. M. \& Maleque, M. A. Effect of process variables on structure and properties of aluminiumsilicon piston alloy. J. Mater. Process. Technol, 77, 122-128 (1998).

2. Haque, M. M. \& Sharif, A. Study on wear properties of aluminium silicon piston alloy. J. Mater. Process. Technol, 118, 69-73 (2001). 
3. Jegdic, B., Bobic, B., Radojkovic, B., Kovacina, J. \& Marunkic, D. Synergistic effect of CeCl3 and benzotriazole on corrosion resistance of naturally aged and artificially aged AA2024 aluminium alloy. Trans. Nonferrous Met. Soc. China, 30, 1478-1490 (2020).

4. Yasmin, T., Khalid, A. A. \& Haque, M. M. Tribological (wear) properties of aluminium-silicon eutectic base alloy under dry sliding condition. J. Mater. Process. Technol, 153, 833-838 (2004).

5. Lakshminarayanan, A. K., Balasubramanian, V. \& Elangovan, K. Effect of welding processes on tensile properties of AA6061 aluminium alloy joints. Int. J. Adv. Manuf. Tech, 40, 286-296 (2009).

6. Rajakumar, S., Muralidharan, C. \& Balasubramanian, V. Influence of friction stir welding process and tool parameters on strength properties of AA7075-T6 aluminium alloy joints. Mater. Des, 32, 535-549 (2011).

7. Hassan, K. A. A., Prangnell, P. B., Norman, A. F., Price, D. A. \& Williams, S. W. Effect of welding parameters on nugget zone microstructure and properties in high strength aluminium alloy friction stir welds, Sci. Technol. Weld. Joining, 8, 257-268 (2003).

8. Yurt, A., Ulutas, S. \& Dal, H. Electrochemical and theoretical investigation on the corrosion of aluminium in acidic solution containing some Schiff bases. Appl. Surf. Sci, 2, 919-925 (2006).

9. Yesudass, S. et al. Experimental and theoretical studies on some selected ionic liquids with different cations/anions as corrosion inhibitors for mild steel in acidic medium. J. Taiwan Inst. Chem. Eng, 64, 252-268 (2016).

10. Chaubey, N., Savita, A., Qurashi, D. S., Chauhan, M. A. \& Quraishi Frontiers and advances in green and sustainable inhibitors for corrosion applications: A critical review. J. Mol. Liq, 321, 114385 (2021).

11. Verma, C., Quraishi, M. A. \& Ebenso, E. E. Quinoline and its derivatives as corrosion inhibitors: A review, Surf. Interfaces, 21, 100634 (2020).

12. Korde, R., Verma, C. B., Ebenso, E. E. \& Quraishi, M. A. Electrochemical and thermo dynamical investigation of 5-ethyl-4-(4-methyxyphenyl)-6-methyl-2-thioxo-1,2,3,4 tetrahydropyrimidine-Scarboxylate on corrosion inhibition behavior of aluminum in $1 \mathrm{M}$ hydrochloric medium,Int. J. Electrochem. Sci. 410(2015)1081-1093.

13. Akande, I. G., Fayomi, O. S. I. \& Oluwole, O. O. Anticorrosion potential of inhibitive suphtrim drug on aluminium alloys in $0.5 \mathrm{M} \mathrm{H}_{2} \mathrm{SO}_{4}$, J. Bio- Tribo- Corros. 6 ( 2020) doi.org/10.1007/s40735-020-00429-9.

14. Lai, X., Hu, J., Ruan, T., Zhou, J. \& Qu, J. Chitosan derivative corrosion inhibitor for aluminium alloy in sodium chloride solution: A green organic/inorganic hybrid. Carbohydr. Polym, 265, 118074 (2021).

15. Arukalam, I. O., Madufor, I. C., Ogbobe, O. \& Oguzie, E. E. Inhibition of mild steel corrosion in sulphuric acid medium by hydroxyethyl cellulose. Chem. Eng. Commun, 202, 112-122 (2015).

16. Eddy, N. O., Momoh-Yahaya, H. \& Oguzie, E. E. Theoretical and experimental studies on the corrosion inhibition potentials of some purines for aluminium in $0.1 \mathrm{M} \mathrm{HCl}, \mathrm{J}$. Adv. Res, 6, 203-217 (2015).

17. Verma, D. K., Dewangan, Y., Dewangan, A. K. \& Asatkar, A. Heteroatom-based compounds as sustainable corrosion inhibitors: An overview. J. Bio- Tribo- Corros, 6, https://doi.org/10.1007/s40735-020-00447-7 (2021). 
18. Udensi, S. C., Ekpe, O. E. \& Nnanna, L. A. Corrosion inhibition performance of low cost and eco-friendly Treculia Africana leaves extract on aluminium alloy AA707-T7351 in $2.86 \% \mathrm{NaCl}$ solutions. Sci. Afr, 12 , e00791 (2021).

19. Ebenso, E. E. et al. Theoretical studies of some sulphonamides as corrosion inhibitors for mild steel in acidic medium. Int. J. Quantum. Chem, 110, 2614-2636 (2010).

20. El-Naggar, M. M. Corrosion inhibition of mild steel in acidic medium by some sulfa drugs compounds. Corros. Sci, 49, 2226-2236 (2007).

21. Verma, C. et al. Aryl sulfonamidomethylphosphonates as new class of green corrosion inhibitors for mild steel in $1 \mathrm{M} \mathrm{HCl}$ : Electrochemical, surface and quantum chemical investigation. J. Mol. Liq, 209, 306-319 (2015).

22. Murulana, L. C., Kabanda, M. M. \& Ebenso, E. E. Experimental and theoretical studies on the corrosion inhibition of mild steel by some sulphonamides in aqueous HCl. RSC Adv, 5, 28743-28761 (2015).

23. Murulana, L. C., Kabanda, M. M. \& Ebenso, E. E. Investigation of the adsorption characteristics of some selected sulphonamide derivatives as corrosion inhibitors at mild steel/hydrochloric acid interface: experimental, quantum chemical and QSAR studies. J. Mol. Liq, 215, 763-779 (2016).

24. Delley, B. From molecules to solids with the DMol3 approach. J. Chem. Phys, 113, 7756-7764 (2000).

25. Hehre, W. J., Ditchfield, K. \& Pople, J. A. Self-consistent molecular orbital methods. XII. Further extensions of gaussian-type basis sets for use in molecular orbital studies of organic molecules. $J$. Chem. Phys, 56, 2257-2261 (1972).

26. Francl, M. M., Pietro, W. J. \& Hehre, W. J. Self-consistent molecular orbital methods. XXIII. A polarizationtype basis set for second-row elements. J. Chem. Phys, 77, 3654-3665 (1982).

27. Guo, L. et al. Theoretical evaluation of the corrosion inhibition performance of 1,3-thiazole and its amino derivatives. Arabian J. Chem, 10, 121-130 (2017).

28. Madkour, L. H. \& Elshamy, I. H. Experimental and computational studies on the inhibition performances of benzimidazole and its derivatives for the corrosion of copper in nitric acid. Int. J. Ind. Chem, 7, 195221 (2016).

29. Obot, I. B. \& Gasem, Z. M. Theoretical evaluation of corrosion inhibition performanceof some pyrazine derivatives. Corros. Sci, 83, 359-366 (2014).

30. Kabanda, M. M., Obot, I. B. \& Ebenso, E. E. Computational study of some amino acid derivatives as potential corrosion inhibitors for different metal surfaces and in different media. Int. J. Electrochem. Sci, 8, 10839-10850 (2013).

31. Jutter, K. Electrochemical impedance spectroscopy (EIS) of corrosion processes on inhomogeneous surfaces. Electrochim. Acta, 35, 1501-1508 (1990).

32. Nam, N. D., Dai, L. T., Mathesi, M., Bian, M. Z. \& Thu, V. T. H. Role of friction stir welding-travelling speed in enhancing the corrosion resistance of aluminium alloy. Mater. Chem. Phys, 173, 7-11 (2016).

33. Njoku, D. I. et al. Natural products for materials protection: corrosion protection of aluminium in hydrochloric acid by kolanitida extract. J. Mol. Liq, 219, 417-424 (2016). 
34. Pang, J. J., Liu, F. C., Liu, J., Tan, M. J. \& Blackwood, D. J. Friction stir processing of aluminium alloy AA7075: microstructure, surface chemistry and corrosion resistance. Corros. Sci, 106, 217-228 (2016).

35. Olasunkanmi, L. O., Obot, I. M., Kabanda, M. M. \& Ebenso, E. E. Some Quinoxalin-6-yl derivatives as corrosion inhibitors for mild steel in hydrochloric acid: experimental and theoretical studies. J. Phys. Chem. C, 119, 16004-16019 (2015).

36. Obayes, H. R. et al. Sulphonamides as corrosion inhibitor: Experimental and DFT studies. J. Mol. Struct, 1138, 27-34 (2017).

37. Sigircik, G., Tuken, T. \& Erbil, M. Assessment of the inhibition efficiency of 3,4-diaminobenzonitrile against the corrosion of steel. Corros. Sci, 102, 437-445 (2016).

38. Eid, S., Abdallah, M., Kamar, E. M. \& El-Etre, A. Y. Corrosion inhibition of aluminium and aluminum silicon alloys in sodium hydroxide solutions by methyl cellulose. J. Mater. Environ. Sci, 6, 892-901 (2015).

39. Sayed, A. R., Saleh, M. M. \& Al-Omair, M. A. H.M. Abd Al-Lateef, Efficient route synthesis of new polythiazoles and their inhibition characteristics of mild steel corrosion in acidic chloride medium. J. Mol. Struct, 1184, 452-461 (2019).

40. Li, J., Birbilis, N. \& Buchheit, R. G. Electrochemical assessment of interfacial characteristics of intermetallic phases present in aluminum alloy 2024-T3. Corros. Sci, 101, 155-164 (2015).

41. Liu, H. et al. Study of corrosion behavior and mechanism of carbon steel in the presence of chlorella vulgaris. Corros. Sci, 101, 84-93 (2015).

42. Murulana, L. C., Singh, A. K., Shukla, S. K., Kabanda, M. M. \& Ebenso, E. E. Experimental and quantum chemical studies for some bis(trifluoromethyl-sulfonyl) imide imidazolium-based ionic liquids as corrosion inhibitors for mild steel in hydrochloric acid solution. Ind. Eng. Chem. Res, 51, 13282-13299 (2012).

43. Ebenso, E. E., Kabanda, M. M., Murulana, L. C., Singh, A. K. \& Shukla, S. K. Electrochemical and quantum chemical investigation of some azine and thiazine dyes as potential corrosion inhibitors for mild steel in hydrochloric acid solution. Ind. Eng. Chem. Res, 51, 12940-12958 (2012).

44. Zarrouk, A., Hammouti, B., Dafali, A. \& Bentis, F. Inhibitive properties and adsorption of purpald as a corrosion inhibitor for copper in nitric acid medium. Ind. Eng. Chem. Res, 52, 2560-2568 (2013).

45. Mehdaoui, R. et al. Corrosion inhibition of carbon steel in hydrochloric acid solution by some synthesized surfactants from petroleum fractions. Res. Chem. Intermed, 42, 5509-5526 (2016).

46. Azzouzi, M. E. et al. Some hydrazine derivatives as corrosion inhibitors for mild steel in $1.0 \mathrm{M} \mathrm{HCl}$ : Weight loss, electrochemical, SEM and theoretical studies. J. Mol. Liq, 221, 633-641 (2016).

47. Faustin, M., Maciuk, A., Salvin, P., Roos, C. \& Lebrini, M. Corrosion inhibition of C38 steel by alkaloids extract of Geissospermum laeve in $1 \mathrm{M}$ hydrochloric acid: Electrochemical and phytochemical studies. Corros. Sci, 92, 287-300 (2015).

48. Liu, Y. et al. Corrosion inhibition of biomimetic super-hydrophobic electrodeposition coatings on copper substrate. Corros. Sci, 94, 190-196 (2015).

49. Lin, Y. et al. Use of HPHT autoclave to determine corrosion inhibition by berberine extract on carbon steels in $3.5 \% \mathrm{NaCl}$ solution saturated with CO2. Int. J. Electrochem. Sci, 10, 194-208 (2015). 
50. Liu, W. et al. Corrosion inhibition of carbon steel in CO2-containing oilfield produced water in the presence of iron-oxidizing bacteria and inhibitors. Corros. Sci, 105, 149-160 (2016).

51. Daoud, D., Douadi, T., Hamani, H., Chafaa, S. \& Al-Noaimi, M. Corrosion inhibition of mild steel by two new S-heterocyclic compounds in $1 \mathrm{M} \mathrm{HCl}$ : Experimental and computational study. Corros. Sci, 94, 2137 (2015).

52. Yadav, M., Kumar, S., Sinha, R. R., Bahadur, I. \& Ebenso, E. E. New pyrimidine derivatives as efficient organic inhibitors on mild steel corrosion in acidic medium: Electrochemical, SEM, EDX, AFM and DFT studies. J. Mol. Liq, 211, 135-145 (2015).

53. Li, X. H., Deng, S. D., Fu, H. \& Mu, G. N. Inhibition by tween-85 of the corrosion of cold rolled steel in 1.0 $\mathrm{M}$ hydrochloric acid solution. J. Appl. Electrochem, 39, 1125-1135 (2009).

54. Qu, Q., Jiang, S., Li, L., Bai, W. \& Zhou, J. Corrosion behavior of cold rolled steel in peracetic acid solutions. Corros. Sci, 50, 35-40 (2008).

55. Deng, S. D., Li, X. H. \& Fu, H. Acid violet 6B as novel corrosion inhibitor for cold rolled steel in hydrochloric acid solution. Corros. Sci, 53, 760-768 (2011).

56. Li, L. et al. Adsorption and corrosion inhibition of Osmanthus Fragran extract on carbon steel. Corros. Sci, 63, 82-90 (2012).

57. Li, X., Deng, S. \& Fu, H. Inhibition of the corrosion of steel in $\mathrm{HCl}, \mathrm{H} 2 \mathrm{SO} 4$ solutions by Bambo leaf extract. Corros. Sci, 62, 163-175 (2012).

58. Deng, S. \& Li, X. Inhibition by Ginkgo leaves extract of the corrosion of steel in $\mathrm{HCl}$ and $\mathrm{H} 2 \mathrm{SO} 4$ solutions. Corros. Sci, 55, 407-415 (2012).

59. Sangeetha, Y., Meenakshi, S. \& Sundaran, C. S. Corrosion inhibition of animated hydroxyl ethyl cellulose on mild steel in acidic condition. Carbohydr. Polym, 150, 13-20 (2016).

60. Kalaiselvi, P., Chellammal, S., Pelanichamy, S. \& Subramanian, G. Artemisia pallens as corrosion inhibitor for mild steel in HCl medium. Mater. Chem. Phys, 120, 643-648 (2010).

61. Ghazoui, A. et al. An investigation of two novel pyridazine derivatives as corrosion inhibitor for C38 steel in 1.0 M HCl. Int. J. Electrochem. Sci, 8, 2272-2292 (2013).

62. Ashassi-Sorkhabi, H. \& Es'haghi, M. Corrosion inhibition of mild steel in acidic media by [BMIm] Br lonic liquid. Mat. Chem. Phys, 1, 267-271 (2009).

63. Ostovari, A., Hoseinieh, S. M., Peikari, M., Shadizadeh, S. R. \& Hashemi, S. J. Corrosion inhibition of mild steel in I $\mathrm{M} \mathrm{HCl}$ solution by henna extract: A comparative study of inhibition by henna and its constituents (Lawsome, Gallic acid, a-D-Glucose and Tannic acid). Corros. Sci, 51, 1935-1949 (2009).

64. Weder, N., Alberto, R. \& Koitz, R. Thiourea derivatives as potent inhibitors of aluminium corrosion: Atomic-level insight into adsorption and inhibition mechanisms. J. Phys. Chem. C, 120, 1770-1777 (2016).

65. Geler, E. \& Azambuja, D. S. Corrosion inhibition of copper in chloride solutions by pyrazole. Corros. Sci, 42, 631-643 (2000).

66. Mashuga, M. E., Olasunkanmi, L. O., Adekunle, A. S., Yesudass, S. \& Kabanda, M. M. E. E. Ebenso, Adsorption, thermodynamic and quantum chemical studies of 1-hexyl-3-methylimidazolium based ionic 
Figures

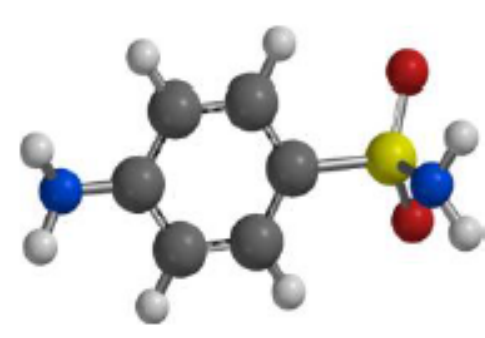

SNA

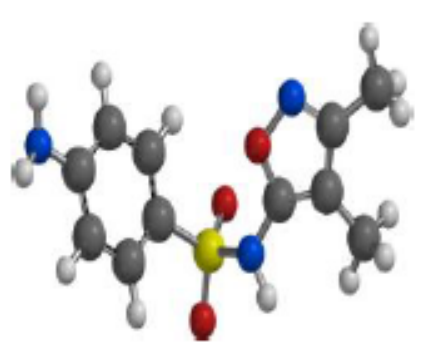

SSZ

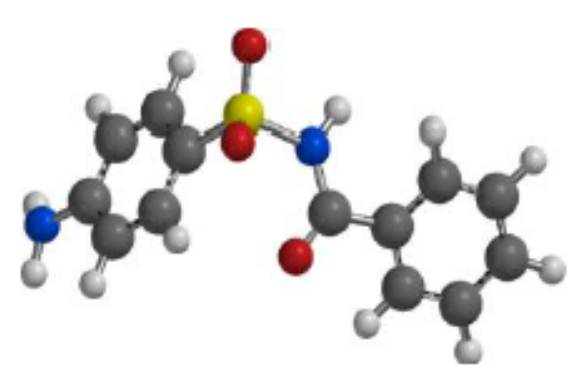

SBZ

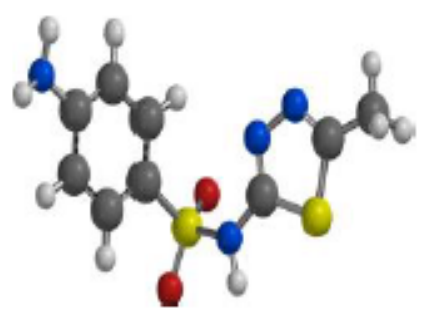

SMZ

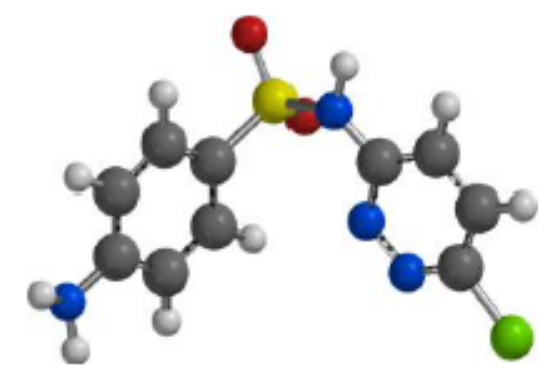

SCP

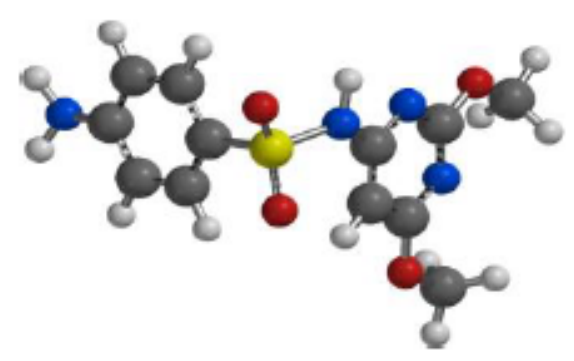

SDM

\section{Figure 1}

The optimized geometries sulphanilamide (SNA), sulphabenzamide (SBZ), sulphachloropyridazine (SCP), sulphisoxazole (SSZ), sulphamethizole (SMZ) and sulphadimethoxine (SDM). 

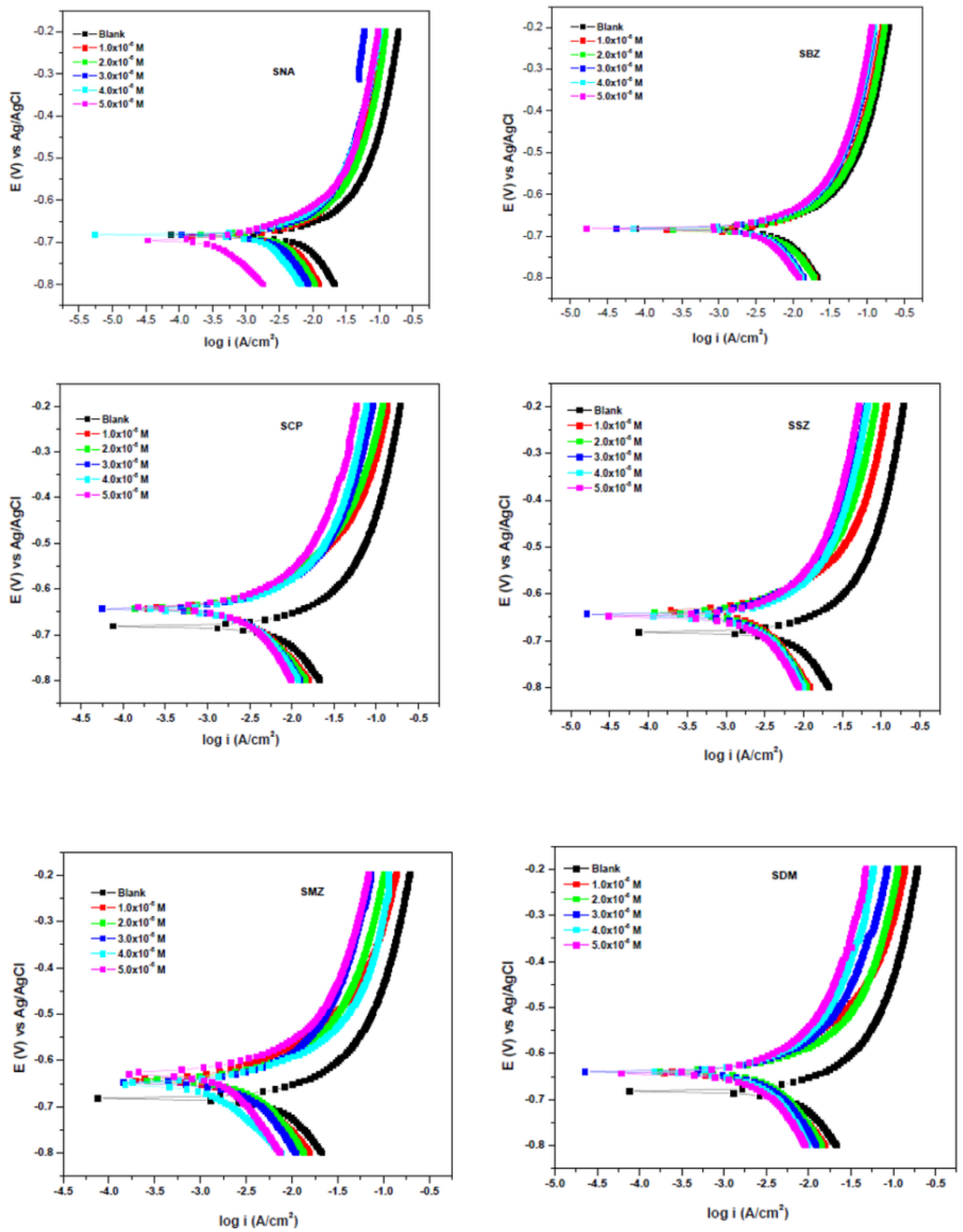

Figure 2

Tafel plots for aluminum in $1 \mathrm{M} \mathrm{HCl}$ in the absence and presence of different concentrations of various inhibitor compounds. 

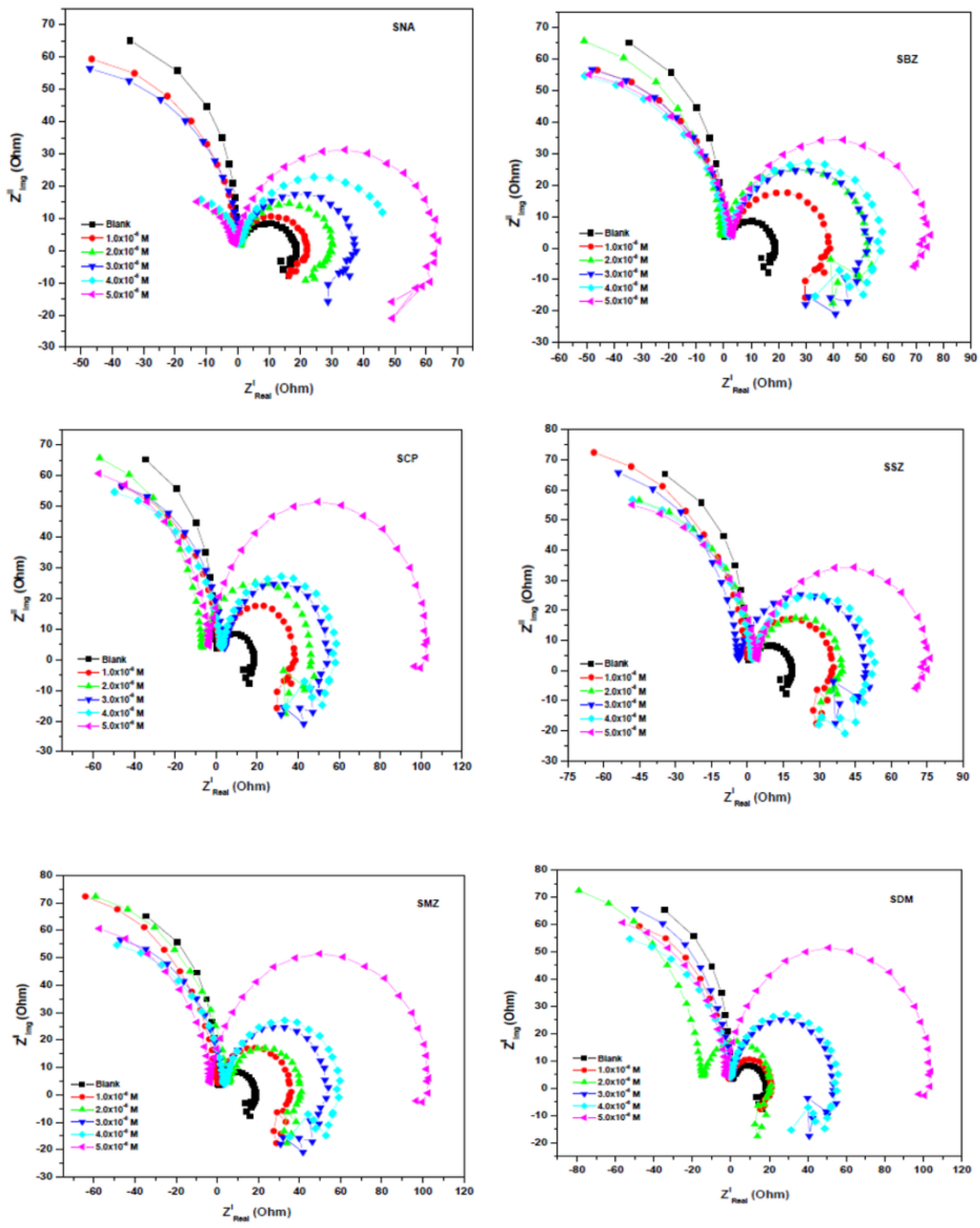

Figure 3

Nyquist plot of aluminium in $1 \mathrm{M} \mathrm{HCl}$ in the absence and presence of different concentrations of various inhibitor compounds. 

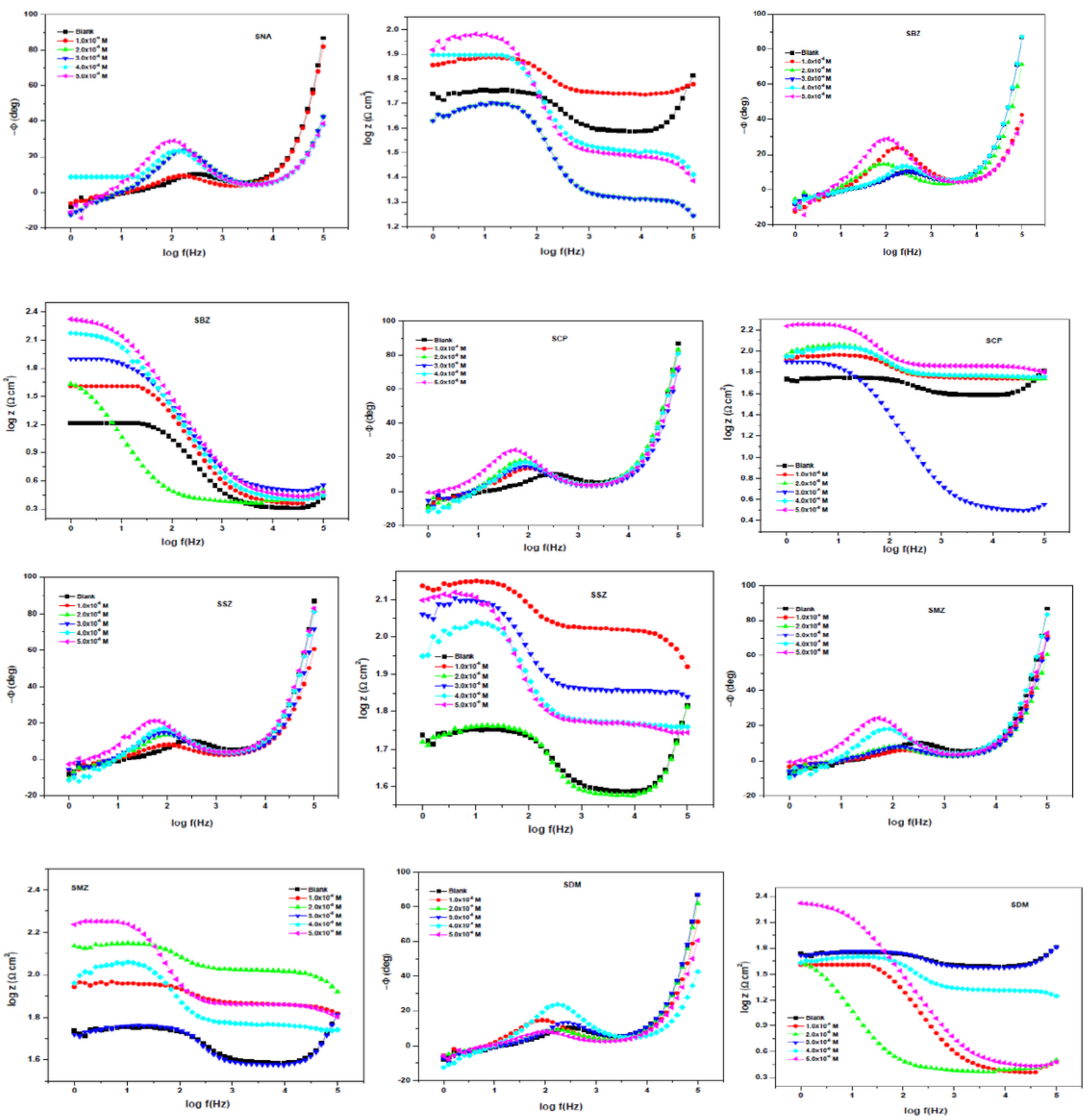

Figure 4

Bode plots of aluminium in $1 \mathrm{M} \mathrm{HCl}$ in the absence and presence of different concentrations of various inhibitor compounds. 


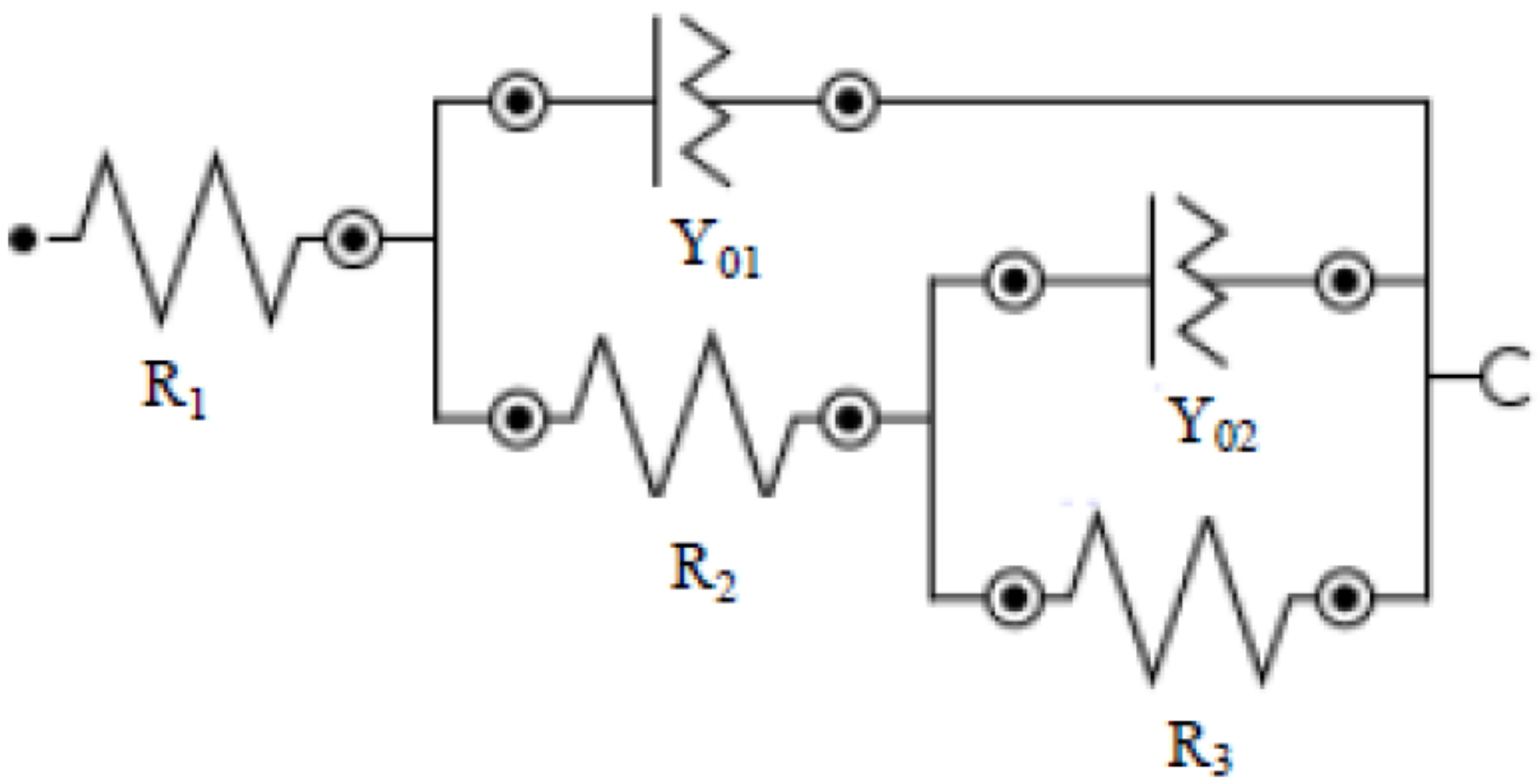

\section{Figure 5}

Equivalent circuit used to fit the impedance spectra obtained for aluminium corrosion in $1.0 \mathrm{M} \mathrm{HCl}$ in the absence and presence of SNA, SBZ, SCP, SDM, SSZ and SMZ. 

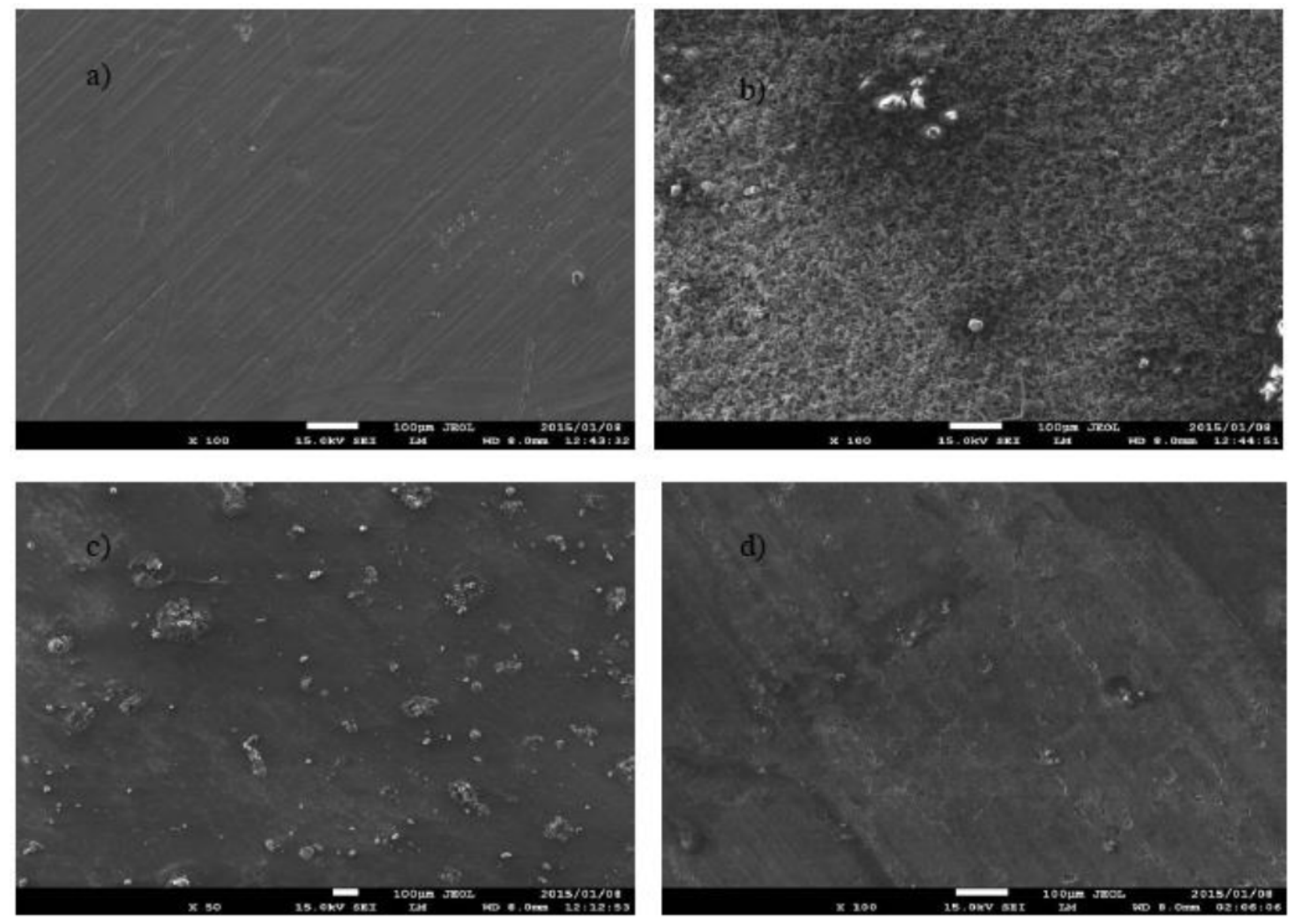

\section{Figure 6}

SEM images of the surfaces of aluminium: a) untreated aluminium b) aluminium immersed in $\mathrm{HCl}$ uninhibited and aluminium immersed in $\mathrm{HCl}$ in the presence of c) SNA d) SBZ 

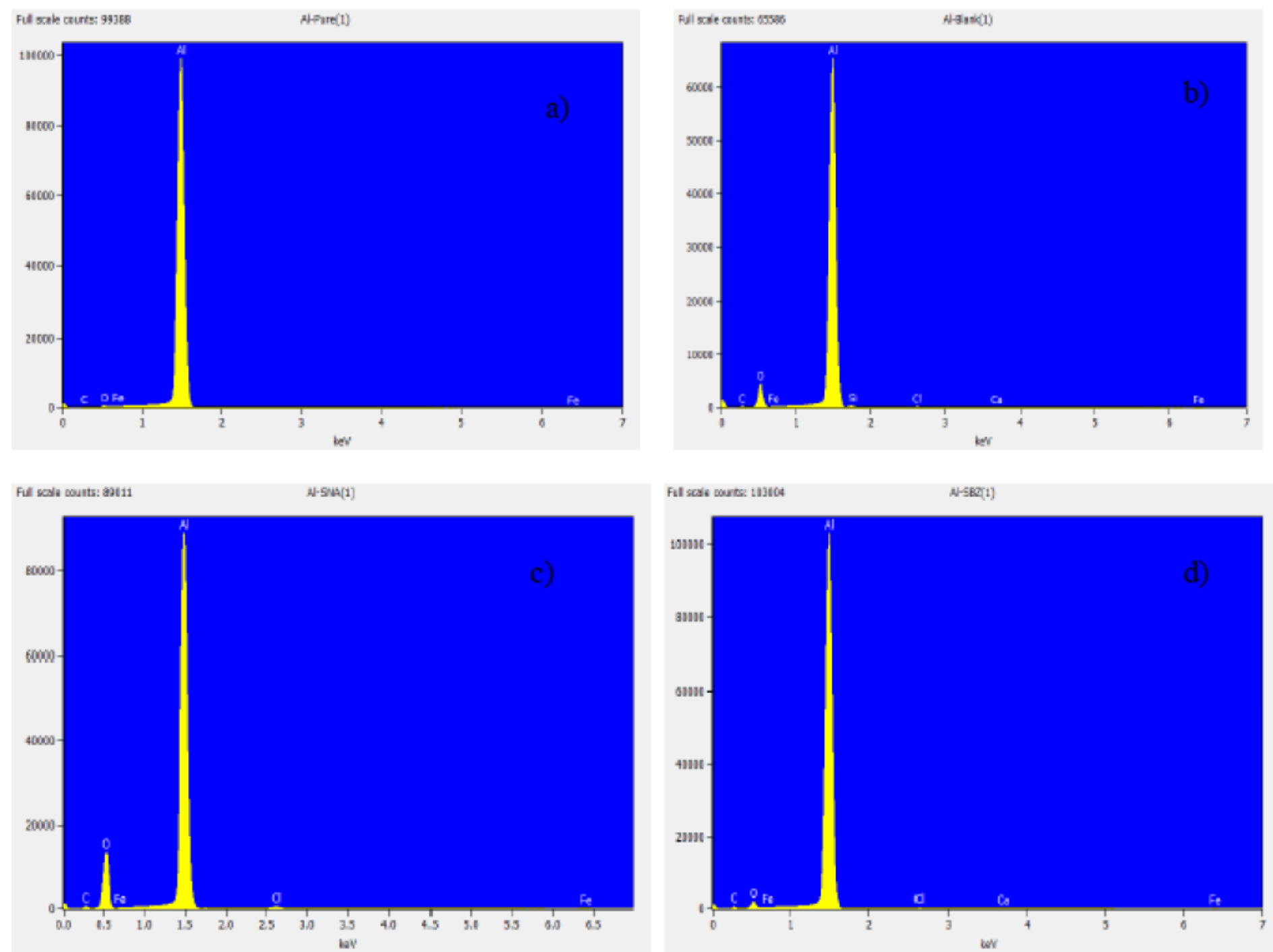

\section{Figure 7}

EDS spectra of the surfaces of aluminium: a) untreated aluminium b) aluminium immersed in $\mathrm{HCl}$ uninhibited and aluminium immersed in $\mathrm{HCl}$ in the presence of c) SNA d) SBZ 

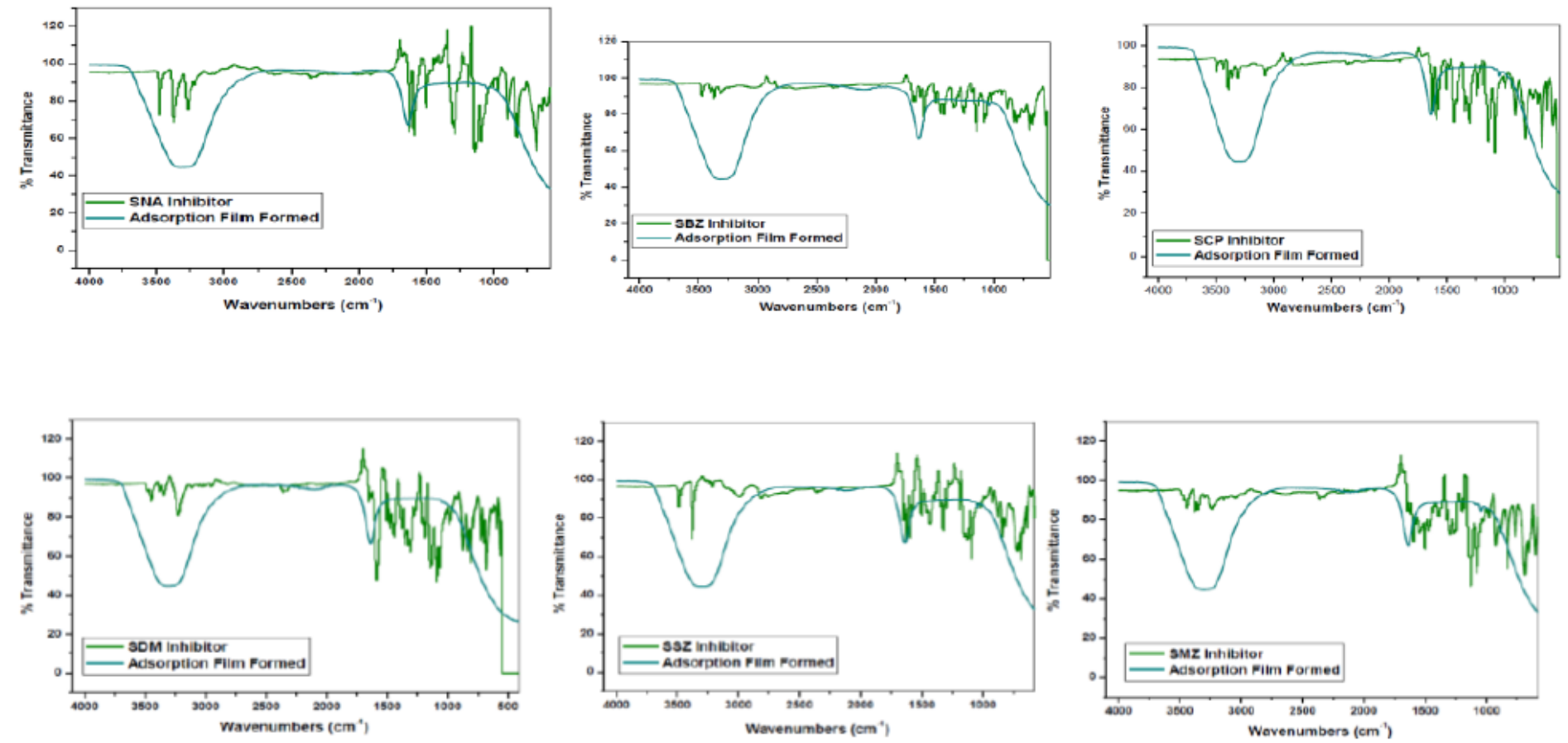

Figure 8

FT-IR spectra for the studied corrosion inhibitors and adsorption films formed on the aluminium in $1.0 \mathrm{M} \mathrm{HCl}$ using for SNA, SBZ, SCP, SDM, SSZ and SMZ.
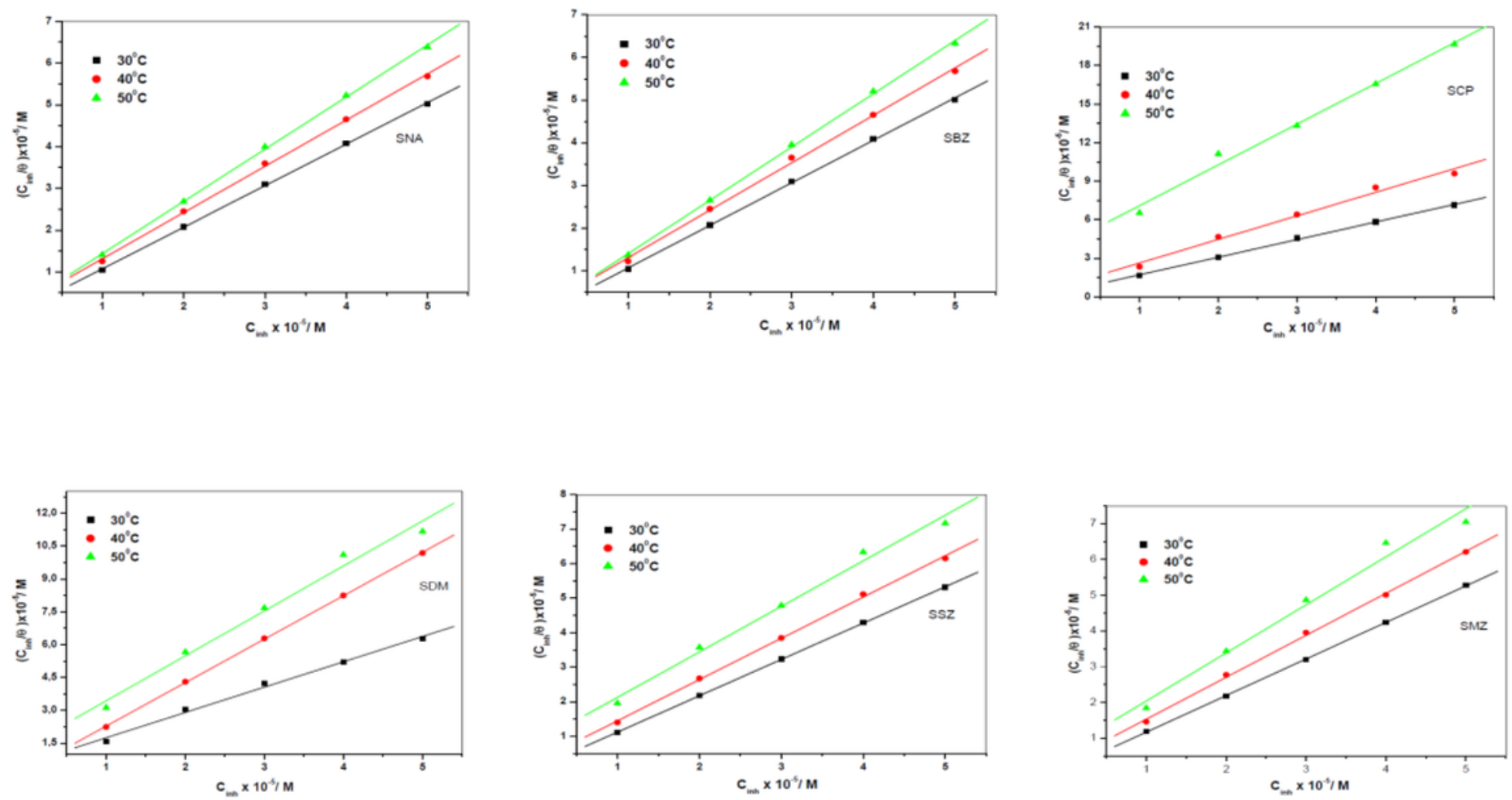

\section{Figure 9}


Langmuir adsorption isotherms for the corrosion of aluminium in $1.0 \mathrm{M} \mathrm{HCl}$ at various temperatures for SNA, SBZ, SCP, SDM, SSZ and SMZ.

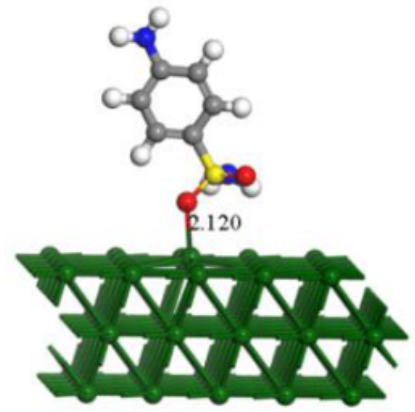

$-24.086 \mathrm{~kJ} / \mathrm{mol}$

SNA

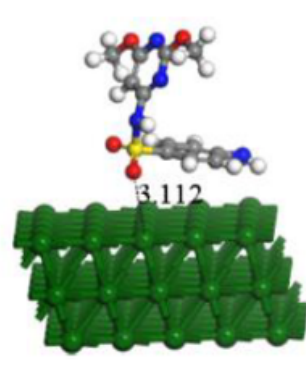

$-18.460 \mathrm{~kJ} / \mathrm{mol}$

SDM

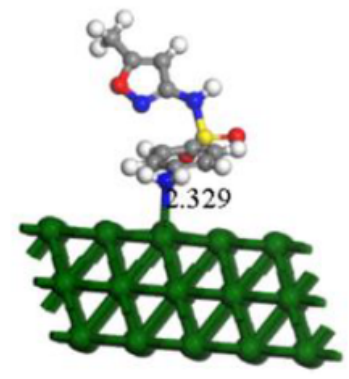

$-31.910 \mathrm{~kJ} / \mathrm{mol}$

SMX

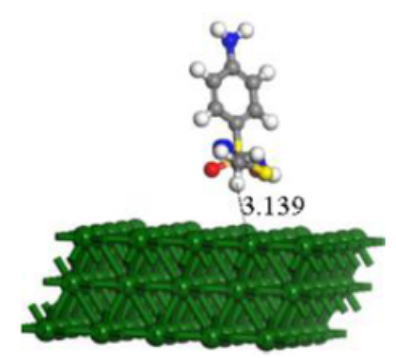

$-23.493 \mathrm{~kJ} / \mathrm{mol}$

SMZ

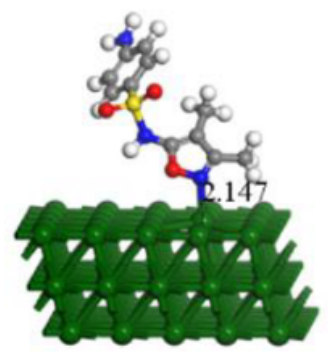

$-38.880 \mathrm{~kJ} / \mathrm{mol}$

\section{Figure 10}

Structures of selected sulphonamides adsorbed on the surface of Al (111) 